\title{
ANALISIS PEMBAGIAN WAKTU KEDATANGAN SUPPLIER PADA INDUSTRI KOMPONEN OTOMOTIF
}

\author{
${ }^{1}$ Ossa Sutaarga, ${ }^{2}$ Dian Friana Hidayat \\ 1,2. Program Studi Teknik Industri, Fakultas Teknik \\ Universitas Muhammadiyah Tangerang \\ Jl. Perintis Kemerdekaan I/33, Cikokol, Kota Tangerang \\ Email : ${ }^{1}$ ossa.sutaarga@gmail.com, ${ }^{2}$ dianfriana@gmail.com
}

\begin{abstract}
A b s trak
Tujuan dari penelitian ini adalah untuk mengetahui dan menganalisa bottleneck yang terjadi saat jam sibuk, agar dapat memberikan masukan atau saran dalam pembagian kedatangan supplier. Tahapan analisa yang dilakukan pertama kali yaitu membuat penjadwalan dalam aktivitas pengamatan, setelah itu melakukan pengamatan terstruktur sesuai dengan jadwal yang sudah dibuat sebelumnya, lalu setiap supplier yang datang akan di record sesuai dengan zona waktu tertentu. Hasil pengamatan penelitian ini diketahui bahwa terjadinya bottleneck terjadi karena jumlah rata-rata kedatangan supplier paling banyak berada di zona waktu 10.00-11.00 yaitu sebanyak 4-5 kali, dan sebanyak 3-4 kali pada zona waktu 14.00-15.00. Jika dibandingkan dengan zona waktu 08.00-09.00 dan 09.00-10.00 maka hasilnya cukup signifikan yaitu hanya 1-2 kali di jam tersebut. Waktu pelayanan yang dibutuhkan setiap kedatangan supplier adalah 20 menit, sehingga pada waktu 10.00-11.00 waktu pelayanan yang terjadi adalah 80 hingga 100 menit, dan pada waktu 14.00-15.00 adalah 60 hingga 80 menit.
\end{abstract}

Kata Kunci : Kedatangan supplier, bottleneck, just in time.

\section{PENDAHULUAN}

Kegiatan produksi merupakan kegiatan menciptakan barang atau part jadi yang berasal dari raw material atau part setengah jadi yang didatangkan dari supplier, (Almahdy, 2009). Komponen-komponen pendukung dalam proses perakitan sebelumnya didatangkan dari supplier yang mana kedatangan tersebut akan diterima oleh bagian warehouse terlebih dahulu. Warehouse dituntut dalam persiapan komponen-komponen yang akan didistribusikan ke Produksi agar tepat waktu. Dengan persiapan komponen-komponen yang akan didistribusikan ke produksi tentunya warehouse akan mengalami kendala dalam pembagian waktu antara distribusi dengan kedatangan supplier.

Dalam kedatangan supplier yang menumpuk di jam tertentu. Kedatangan supplier yang bottleneck di jam-jam sibuk ini terjadi karena tidak adanya jadwal untuk supplier. Supplier datang diwaktu bersamaan sering kali membuat karyawan gudang kewalahan, sedangkan di jam kosong karyawan gudang menjadi mengganggur. Kedatangan supplier yang menumpuk ini membuat kinerja karyawan gudang menjadi tidak efektif, dimana hal ini menimbulkan kerugian bagi perusahaan.

Tujuan dari penelitian ini adalah untuk mengetahui dan menganalisa bottle neck yang terjadi saat jam sibuk agar penulis dapat memberikan masukan atau saran dalam pembagian kedatangan supplier. Dengan hasil analisa tersebut diharapkan agar bottle neck yang terjadi bisa diratakan (mura) pada jam kosong agar tidak ada waktu mengganggur atau terbuang di jam-jam tertentu. 


\section{METODE PENELITIAN}

Dalam melakukan tahap analisa kedatangan supplier ini hal yang dilakukan pertama kali adalah membuat penjadwalan dalam aktivitas pengamatan, setelah itu melakukan pengamatan terstruktur sesuai dengan jadwal yang sudah dibuat sebelumnya, lalu mengamati setiap supplier yang datang akan di record sesuai dengan zona waktu tertentu. Pembagian zona waktu tersebut sebagai berikut :

Tabel 1. Zona Kedatangan Supplier

\begin{tabular}{|c|c|c|c|c|c|}
\hline No. & Zona Waktu & Supplier & No. & Zona Waktu & Supplier \\
\hline 1 & $08.00-09.00$ & & 5 & $13.00-14.00$ & \\
\hline 2 & $09.00-10.00$ & & 6 & $14.00-15.00$ & \\
\hline 3 & $10.00-11.00$ & & 7 & $15.00-16.00$ & \\
\hline 4 & $11.00-12.00$ & & 8 & $16.00-17.00$ & \\
\hline
\end{tabular}

Dari pembagian waktu di tabel 1 menjelaskan pembagian zona waktu tersebut dibagi zona waktu setiap per-jam.Dimana pengambilan data ini dilakukan selama 1 bulan kerja full rutin setiap harinya dibulan Oktober 2017. Hal ini nantinya akan bertujuan untuk mengetahui zona berapakah untuk kedatangan supplier paling banyak. Total supplier dari PT. X adalah sebanyak 43 supplier local aktif, yang mana nantinya akan diketahui supplier yang paling banyak datang dan yang paling sedikit datang didalam bulan periode pengamatan. Lalu akan diketahui juga untuk rata-rata kedatangan supplier per hari-nya dan per zona waktu.

Setelah pengambilan data maka akan dilakukan analisa terhadap bottleneck yang terjadi disetiap kedatangan supplier. Hasil analisa ini pula yang nantinya akan menjadi saran perbaikan. Berikut tahapan pengamatan yang dibuat.

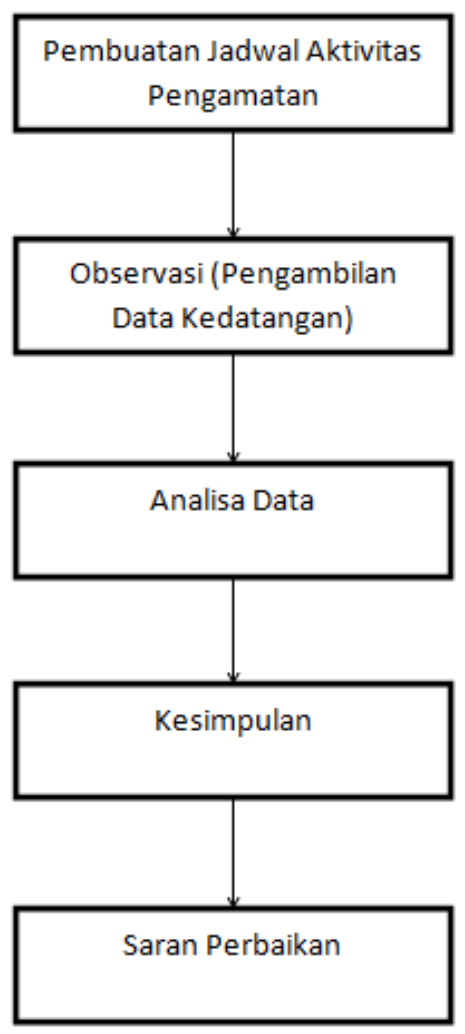

Gambar 1. Langkah-langkah Pengambilan Data 


\section{HASIL DAN PEMBAHASAN}

Dari langkah-langkah pengamatan yang dijelaskan di metode penilitian, jadwal aktivitas yang akan dilakukan pada saat pengambilan data tersebut adalah

Tabel 2 Penjadwalan Aktivitas dalam Pengamatan Kedatangan Supplier

\begin{tabular}{|c|c|c|c|c|c|c|c|c|c|c|c|c|c|c|c|c|c|c|c|}
\hline \multirow{3}{*}{ No. } & \multirow{3}{*}{ Activity } & \multirow{3}{*}{ Plan Vs Act } & \multicolumn{12}{|c|}{2017} & \multirow{2}{*}{\multicolumn{4}{|c|}{$\begin{array}{c}2018 \\
\text { Januari }\end{array}$}} & \multirow{3}{*}{$\begin{array}{c}\text { Total } \\
\text { (weeks) }\end{array}$} \\
\hline & & & \multicolumn{4}{|c|}{ October } & \multicolumn{4}{|c|}{ November } & \multicolumn{4}{|c|}{ Desember } & & & & & \\
\hline & & & 1 & 2 & 3 & 4 & 1 & 2 & 3 & 4 & 1 & 2 & 3 & 4 & 1 & 2 & 3 & 4 & \\
\hline \multirow{2}{*}{1} & Pengambilan Data & $\mathrm{P}$ & & & & & & & & & & & & & & & & & 4 \\
\hline & Kedatangan Material & A & & & & & & & & & & & & & & & & & \\
\hline \multirow{2}{*}{2} & Pembagian waktu kedatangan & $\mathrm{P}$ & & & & & & & & & & & & & & & & & 2 \\
\hline & Supplier & A & & & & & & & & & & & & & & & & & \\
\hline \multirow{2}{*}{3} & Visit Supplier & $\mathrm{P}$ & & & & & & & & & & & & & & & & & 2 \\
\hline & & A & & & & & & & & & & & & & & & & & \\
\hline \multirow{2}{*}{4} & Analisa Data & $\mathrm{P}$ & & & & & & & & & & & & & & & & & 1 \\
\hline & & A & & & & & & & & & & & & & & & & & \\
\hline \multirow{2}{*}{5} & Evaluasi Supplier & $\mathrm{P}$ & & & & & & & & & & & & & & & & & 2 \\
\hline & & A & & & & & & & & & & & & & & & & & \\
\hline & Total Aktivitas & & & & & & & & & & & & & & & & & & 11 \\
\hline
\end{tabular}

Gambar diatas adalah jadwal yang dibuat untuk menjadwalkan pengamatan kedatangan supplier setiap harinya selama di bulan Oktober 2017. Dalam aktivitas pengambilan data yaitu sebanyak 4 minggu kerja, dimana 1 minggu kerja ada 5 hari kerja atau 40 jam kerja. Pada tabel 1.2 aktivitas-aktivitas lainnya juga dijadwalkan sampai dengan aktivitas Evaluasi Supplier. Perencanaan total penjadwalan tersebut sebanyak 11 minggu sampai dengan evaluasi supplier. Setelah penjadwalan dibuat, aktivitas-aktivitas yang telah dibuat sebelumnya dilaksanakan, dimana aktivitas pertama yaitu mengamati kedatangan supplier di setiap harinya di jam-jam yang sudah dibagi per zona waktu tersebut.

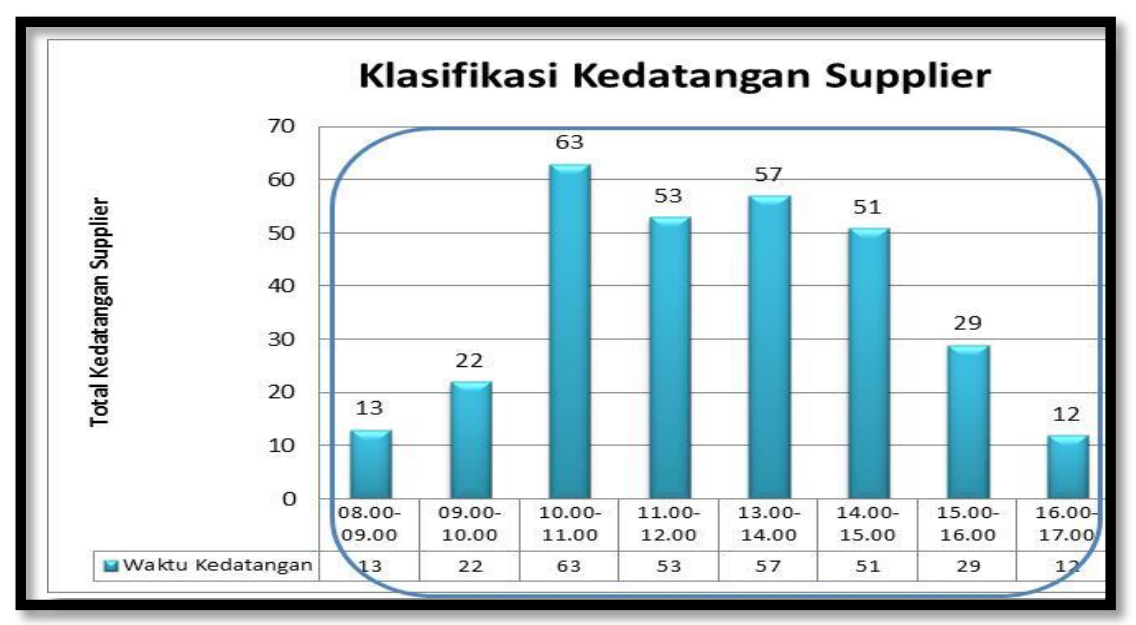

Gambar 2. Diagram Batang Jumlah Supplier Datang (Hasil Pengamatan 1 bulan)

Hasil pengamatan selama di bulan Oktober 2017, jika dilihat per zona waktu yang telah di tentukan, bahwa kedatangan supplier paling banyak berada di zona waktu jam 10.00-11.00, 63 kali datang di jam tersebut, sampai zona waktu 14.00-15.00, 51 kali datang di jam tersebut. jika kita lihat data tersebut berbanding sangat jauh dengan zona waktu 08.00-09.00, 13 kali datang di jam tersebut dan 09.00-10.00, 22 kali datang di jam tersebut.

Jika data tersebut kita ubah kedalam bentuk rata-rata kedatangan supplier di jam tersebut hasilnya seperti gambar berikut : 


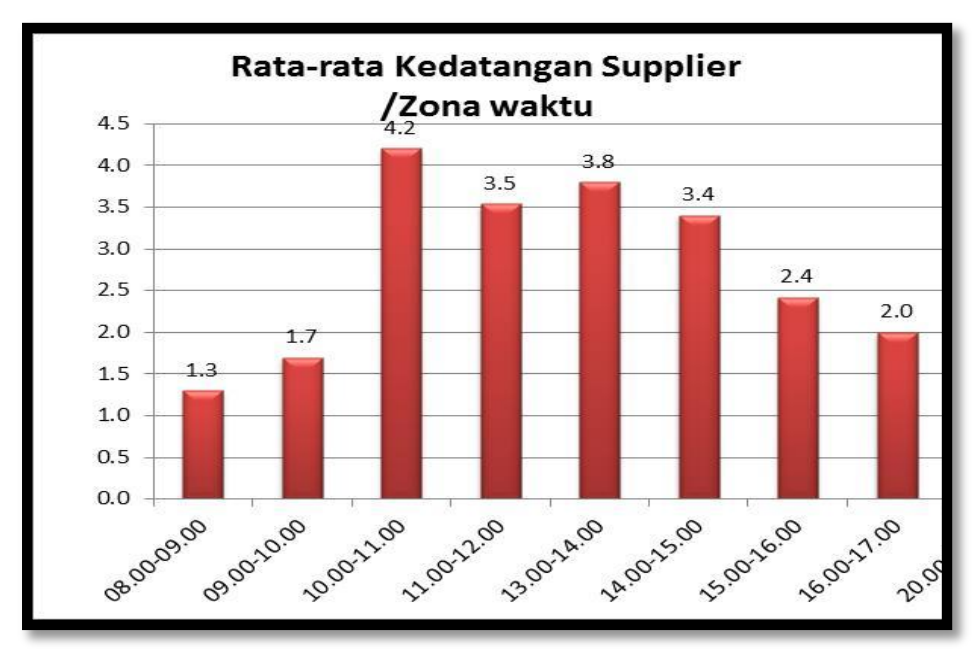

Gambar 3. Rata-rata Kedatangan Supplier per Zona Waktu

Dari gambar diatas dijelaskan bahwa range di zona waktu pukul 10.00-11.00, rata-rata kedatangan 4.2 kali atau bisa dikatakan 4-5 kali datang di zona tersebut sampai dengan 14.0015.00, 3.4 kali datang atau bisa dikatakan 3-4 kali datang di zona tersebut. Hal ini berbanding sangat jauh dengan zona waktu pagi pukul 08.00-09.00, 1.3 kali datang atau bisa dikatakan 1-2 kali datang di jam tersebut dan zona waktu pukul 09.00-10.00, 1.7 kali datang atau bisa dikatakan 1-2 kali datang di zona waktu tersebut.

Hasil pengamatan tersebut menjelaskan tidak meratanya kedatangan supplier di jam-jam tersebut. Dimana beban yang paling tinggi terjadi pada pukul 10.00-11.00, sampai dengan 14.0015.00. Hal ini menyebabkan di zona waktu pagi pukul 08.00-09.00 sampai dengan 09.00-10.00 terjadi idle time atau waktu menganggur di jam tersebut. Namun untuk di zona waktu 10.00-11.00 sampai dengan 14.00-15.00 terjadi penumpukan kedatangan supplier sehingga terjadi bottleneck. Rata-rata pelayanan supplier \pm 20 menit sehingga apabila supplier datang dijam sibuk sebanyak 4-5 supplier, artinya operator gudang membutuhkan waktu melayani $\pm 80-100$ menit. Hal ini lah yang menyebabkan terjadinya bottleneck saat melayani supplier sehingga antrian yang terakumulasi di setiap zona waktunya. Terlebih lagi pukul 16.00-17.00 adalah waktu dimana operator Gudang membuat persiapan material untuk shift 2 produksi. Karena aktivitas-aktivitas melayani antrian supplier tadi maka persiapan material dari warehouse yang harus didistribusikan ke produksi menjadi terhambat dan berdampak terjadinya overtime disetiap harinya.

\section{KESIMPULAN}

1. Pengamatan yang diambil oleh penulis selama 1 bulan kerja dibulan oktober 2017 dengan cara observasi ke gudang dilokasi incoming material. Pengamat merecord jam kedatangan supplier di setiap kali supplier datang.

2. Dari zona waktu yang ditentukan terdapat 4 zona waktu yang memiliki angka tertinggi yaitu range waktu antara zona 10.00-11.00 sampai dengan zona waktu 14.00-15.00. dimana untuk kedatangan waktu tersebut disebut dengan jam-jam sibuk dan terjadi bottleneck antara kapasitas manpower di incoming material dengan jumlah kedatangan supplier.

3. Rata-rata kedatangan supplier di jam sibuk tersebut terdapat 4-5 supplier dimana setiap kali pelayanan menghabiskan waktu \pm 20 menit, sehingga bottleneck terjadi ketika operator gudang belum selesai melayani supplier di zona waktunya maka sudah ada kedatangan supplier berikutnya. 


\section{SARAN}

1. Saran perbaikan dari penulis dalam hasil pengamatan ini adalah organisasi harus memulai membagi kedatangan supplier dengna cara meratakan beban yang terjadi saat ini agar bisa mengurangi waktu idle di zona waktu 08.00-09.00 sampai dengan 09.00-10.00. hal ini diharapkan dapat mengurangi bottleneck akibat dari melayani antrian supplier yang datang di jam sibuk.

2. Untuk meratakan beban kedatangan supplier perusahaan harus mengatur waktu kedatangan supplier dimulai dengan mengklasifikasikan dan menganalisa supplier yang datang total supplier yang aktif sebanyak 43 supplier. Saran dari penulis untuk mengklasifikasikan supplier harus melihat dari :

- Jarak tempuh supplier

- $\quad$ Analisa jam kedatangan supplier disetiap kali datang

- $\quad$ Hitung beban pelayanan setiap supplier

- $\quad$ Pembagian supplier max 3 supplier di setiap zona waktu

\section{DAFTAR PUSTAKA}

Almahdy, I., \& Prawira, E. T. (2009). Desain Sistem Kedatangan Part Supplier Berbasis JIT Pada Perusahaan Industri Komponen Otomotif. Jurnal Sinergi, 3(1).

Masruroh, N. A., \& Prasetyorini, A. V. (2015). Model Penjadwalan Pengiriman Pasokan pada Strategi Multi-Supplier dengan Variasi Harga dan Lead Time untuk Permintaan Stokastik. Jurnal Teknik Industri, 17(1), 35-46.

Prayogo, A., \& Sutapa, I. N. (2015). Upaya Peningkatan Kinerja Departemen Warehouse di PT. X. Jurnal Titra, 3(2), 241-246.

Sembiring, A. C. (2008). Penentuan Rute Distribusi Produk Yang Optimal Dengan Menggunakan Algoritma Heuristik Pada PT. Coca-Cola Bottling Indonesia Medan.

Sulianto, A. (2005). Penjadwalan Kedatangan Supplier Di Bagian Part Preparation I PT. Astra Honda Motor-Pegangsaan Plant. (Doctoral dissertation, Universitas Sebelas Maret). 
